\title{
Echocardiographic characteristics of aortic intramural hematoma for the differentiation from atheromatous plaques and mural thrombi in the aorta
}

\author{
Kazuhiro Nishigami
}

Received: 6 May 2011/Accepted: 12 May 2011/Published online: 27 May 2011

(C) Japanese Society of Echocardiography 2011

Aortic intramural hematoma (IMH) is known to be an atypical aortic dissection based on vasa vasorum hemorrhage, which is characterized by the absence of continuous blood flow in the false lumen [1]. The prevalence of IMH is more frequent in the elderly population and increases worldwide. Cardiovascular echo can play an important role as a first diagnostic procedure for diagnosing IMH in the emergency room and regional thickening of the aortic wall can be a specific finding for IMH on aortic echo [2]. It could, however, be difficult to differentiate IMH from atheromatous plaques and mural thrombi in the aorta, although atheroma and thrombus might be characterized as high echo density protruding into the lumen of the aorta and laminar mass localized in the aneurysm, respectively [3]. I reviewed the echocardiographic characteristics of IMH for the differentiation from atheromatous plaques and mural thrombi in the aorta based on several textbooks [1-3] and summarized them in the following table.

\begin{tabular}{llll}
\hline & $\begin{array}{l}\text { Intramural } \\
\text { hematoma }\end{array}$ & Mural thrombi & $\begin{array}{l}\text { Atheromatous } \\
\text { plaque }\end{array}$ \\
\hline $\begin{array}{l}\text { Surface } \\
\text { Shape }\end{array}$ & $\begin{array}{l}\text { Smooth } \\
\text { Crescent or circular }\end{array}$ & $\begin{array}{l}\text { Irregular } \\
\text { Half-round }\end{array}$ & $\begin{array}{l}\text { Undulating } \\
\text { Cobblestone } \\
\text { appearance }\end{array}$ \\
$\begin{array}{l}\text { Lucency } \\
\text { Spread }\end{array}$ & Echolucency & $\begin{array}{l}\text { Laminar } \\
\text { Extensive }\end{array}$ & $\begin{array}{l}\text { High } \\
\text { the aneurysm }\end{array}$ \\
& & Scattering \\
\hline
\end{tabular}

K. Nishigami $(\bowtie)$

Department of Critical Care and Cardiology,

Saiseikai Kumamoto Hospital, 5-3-1 Chikami,

Kumamoto 861-4193, Japan

e-mail: kazuhiro-nishigami@saiseikaikumamoto.jp
IMH has been recognized to be relatively associated with aortic sclerosis (Fig. 1) compared to overt aortic dissection [1]. The present findings suggesting IMH (smooth surface, crescent shape, echolucency, and extensive spread) could be recalled as sclerosis.

Although these characteristics presented here might not be absolute for discriminating IMH from atheromatous plaque and mural thrombi in the aorta, they provide knowledge on the evaluation of IMH using cardiovascular echo.

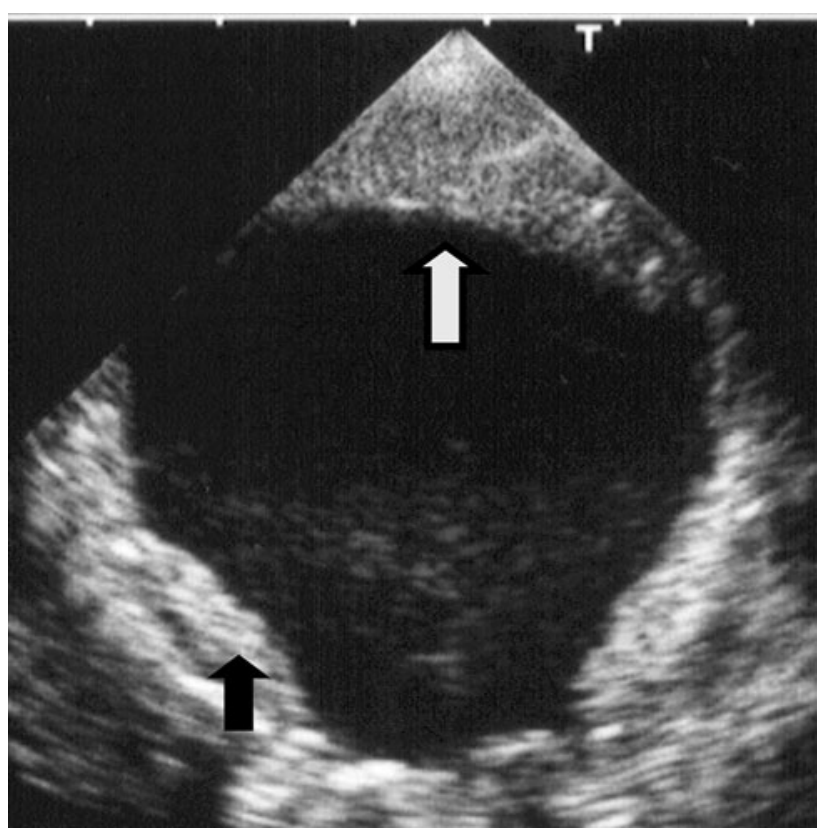

Fig. 1 Transesophageal echocardiographic image of intramural hematoma (white arrow) in the descending aorta. Atherosclerosis (black arrow) was also observed 


\section{References}

1. Bonow RO, Mann DL, Zipes DP, Libby P. Braunwald's heart disease: a textbook of cardiovascular medicine. Philadelphia: Saunders; 2011.
2. Armstrong WF, Ryan T. Feigenbaum's echocardiography. Philadelphia: Lippincott Williams \& Wilkins; 2009.

3. Oh JK, Seward JB, Tajik AJ. The Echo manual. Philadelphia: Lippincott Williams \& Wilkins; 2006. 